\title{
MUTAÇÃO CONSTITUCIONAL Origem, (Des)Construção e Justificação
}

Dissertação de Mestrado

Orientador: Professor Dr. Roger Stiefelmann Leal

UNIVERSIDADE DE SÃO PAULO

FACULDADE DE DIREITO

SÃO PAULO - SP

2017 


\section{MUTAÇÃO CONSTITUCIONAL Origem, (Des)Construção e Justificação}

Dissertação apresentada à Banca Examinadora do Programa de PósGraduação em Direito, da Faculdade de Direito da Universidade de São Paulo, como exigência parcial para obtenção do título de Mestre em Direito, na área de concentração Direito do Estado, sob a orientação do Professor Dr. Roger Stiefelmann Leal.

UNIVERSIDADE DE SÃO PAULO

FACULDADE DE DIREITO

SÃO PAULO - SP

2017 
Para Murillo, pela paciência com esse sonho, enquanto compartilhávamos outros. 


\section{AGRADECIMENTOS}

Essa é uma pesquisa que verdadeiramente teve uma história, que superou todas as minhas expectativas em riqueza e dimensão. Ela se desenvolveu entre quatro países e dois continentes, ao longo dos três anos que me foram conferidos, e com o auxílio indispensável de dezenas de indivíduos, entre pesquisadores, mentores e amigos. Como consequência, tenho muito o que agradecer.

Começo por onde tudo tem inicio: agradeço a Deus, acima de tudo. À minha família José, Márcia e João Vítor Robalinho - todos os agradecimentos parecem insuficientes; são meu norte e minha rocha, sem os quais nada poderia ser alcançado. Meus brilhantes pais sempre combinaram apoio, incentivo e exemplo. Essa combinação é o motor que impulsiona meus passos, em todas as fases da vida. Sempre tive consciência do privilégio que significa fazer parte dessa família; sou imensamente grata.

Meu pai, José Robalinho, com o qual compartilho minha profissão, é uma influência que se reflete não apenas neste, mas em todos os trabalhos que já produzi; dele herdei o amor pelos livros, pela história, pelo saber. Como foi costume e regra durante toda a minha vida, esse trabalho foi enriquecido pelas nossas discussões sobre o tema, e por seus comentários no produto final. Por isso, e por tudo, muito obrigada.

A Murillo, amor da minha vida, também é difícil agradecer. Nada se concretizaria sem a sua presença e o seu apoio. Esse mestrado frequentemente cobrou seu preço sobre o nosso tempo e os nossos planos, mas esse apoio nunca deixou de ser entusiasmado e incondicional. Por isso esse trabalho, como todo o resto, é seu.

Sempre me apoiei nas amizades, e sempre me senti imensamente afortunada nesse quesito; esse período não foi diferente. A Isabella, Tatiane, Gabriel, Luís Felipe, Igor, Gabriela, Ludmilla, Ricardo e Luana, agradeço por esse encontro de almas de oferece doses iguais e necessárias de apoio e leveza ao dia-a-dia, perto ou longe. Tudo - inclusive a confecção desse trabalho - é mais fácil porque os tenho comigo. 
Às minhas irmãs da vida - Andressa, Maria Fernanda, Fernanda, Isabela, Carina e Isabella - agradeço pela amizade que já soma quase quinze anos, e que retém a simplicidade de quando começou. Essa simplicidade só se torna mais necessária conforme os anos passam.

Também preciso (continuar a) agradecer de forma especial a Hazenclever Júnior, meu companheiro de aventuras acadêmicas, que se dispõe a discutir incansavelmente os temas constitucionais que sempre nos foram caros, com resultados cujo valor não pode ser mesurado, para esse trabalho e muito além dele. Mas ademais desses debates lhe agradeço por entender, talvez melhor do que ninguém, os sonhos que levam por esses caminhos acadêmicos que temos compartilhado.

Em abril de 2014, no meu primeiro semestre como aluna do mestrado, tive a oportunidade de assistir ao seminário avançado sobre mutações constitucionais, que se realizou na Universidade de Lisboa. As discussões travadas por grandes constitucionalistas brasileiros e europeus sobre o tema naquela oportunidade foram fundamentais para o desenvolvimento das percepções que permearam esse trabalho. Tenho que agradecer de maneira especial aos que me proporcionaram essa chance.

O Professor Carlos Blanco de Morais, que lecionou na primeira matéria que assisti como aluna do mestrado, foi generoso diante do meu interesse pelo estudo da mutação constitucional. Forneceu, gentilmente, um exemplar de seu próprio trabalho sobre o tema, e fez o primeiro convite para que eu fosse a Lisboa participar do seminário, que teve um papel fundamental em organizar. Por sua atenção e pelo convite, muito obrigada.

O Ministro Gilmar Ferreira Mendes me concedeu, desde a graduação, oportunidades ímpares de me beneficiar de seus extensos conhecimentos constitucionais, sobre os temas dessa dissertação e tantos outros presentes em inúmeras discussões. Foi graças a ele que pude efetivamente viajar a Portugal, quando atuava como sua assistente acadêmica, um trabalho que me trouxe valiosas oportunidades e aprendizados. Por essas e por muitas outras circunstâncias, lhe sou intensamente grata. 
O meu orientador, Professor Roger Stiefelmann Leal, reforçou o convite e ajudou a concretizar minha participação no seminário, além de apresentar, como palestrante, perspectivas preciosas ao nosso debate sobre o tema da mutação constitucional. Outros agradecimentos virão, mas destaco esse de forma especial.

Em minha banca de qualificação, os Professores Conrado Hübner Mendes e Anna Cândida da Cunha Ferraz contribuíram com comentários e críticas fundamentais, que auxiliaram em fechar caminhos desnecessários e em abrir outros, que renderam muitos frutos. Agradeço-lhes pela atenção e pelo esforço, e espero ter atendido aos seus questionamentos no produto final.

Após minha qualificação iniciei uma nova etapa de pesquisa, na qual toda sorte de gratidão é devida a Universidade de Yale, aonde completei o programa do LL.M. entre agosto de 2015 e maio de 2016. Os indescritivelmente talentosos pesquisadores que dividiram comigo os nove meses na Yale Law School formavam um grupo único, do qual me sinto imensamente privilegiada por ter feito parte. Seria impossível a qualquer um não se beneficiar academicamente de sua companhia, mas muito além da academia eles me ofereceram apoio incondicional e amizade. Muitíssimo obrigada.

Muitas razões, grandes e pequenas, justificariam um agradecimento especial para Juliana Pondé Fonseca; mas vou destacar apenas a gratidão porque, com a generosidade habitual e alma de professora, ela me ensinou pacientemente a navegar o programa de organização de bibliografia Zotero - sem o qual, verdadeiramente, esse trabalho não teria sido completado.

Bruce Ackerman foi infinitamente generoso, com seu tempo e com seus conselhos, literalmente do primeiro ao último dia em que estive em Yale. Como sua aluna em duas disciplinas, sua assistente acadêmica e orientanda de pesquisa, me favoreci imensamente de nossas discussões, e da influencia de seu pensamento. Essas extensas oportunidades de trabalho e debate seriam motivo mais do que suficiente para expressar gratidão, mas o Professor Ackerman também me ofereceu apoio e incentivo indiscriminadamente. Os benefícios se estendem muito além desse trabalho, e sou imensamente grata.

Ao me contratar como assistente de pesquisa, Richard Albert me brindou com a oportunidade de trabalhar com um dos maiores especialistas em mudanças constitucionais da 
atualidade. Acompanhando sua pesquisa e suas aulas adquiri novas perspectivas sobre esse trabalho, sobre o qual debatemos em diversas ocasiões, e que foi amplamente melhorado por seus conselhos e observações. Por sua orientação e por sua amizade, muito obrigada.

Esse período ainda me brindou com oportunidades antes inimagináveis de ver de perto o trabalho de alguns dos maiores constitucionalistas da atualidade. Mas os Professores que me acolheram com interesse e dedicação em suas salas de aula (e além delas) merecem um agradecimento especial: a Jack Balkin, Reva Siegel, Akhil Amar e Philip Bobbitt, cuja influência pode ser sentida ao longo desse trabalho, muito obrigada.

Por fim, em julho de 2016, mais uma oportunidade de pesquisa se mostraria fundamental na confecção dessa dissertação: a de integrar a escola de verão do Instituto Max Planck de História do Direito Europeu, em Frankfurt am Main. O contato que me foi proporcionado com os textos originais e traduções selecionadas da doutrina alemã dos séculos XIX e XX, aos quais dificilmente teria acesso em outro contexto, foi absolutamente fundamental para a confecção do primeiro capítulo, assim como a paciência e o interesses de professores e pesquisadores que se dispuseram a responder minhas incessantes perguntas. Ao Instituto e a seus pesquisadores, credito a primeira seção desse trabalho, e estendo meus efusivos agradecimentos.

$* * * *$

Os agradecimentos finais são voltados ao Programa de Pós-graduação em Direito da Universidade de São Paulo, que me abriu todas as portas para as incríveis oportunidades que enriqueceram essa pesquisa; a todos os professores do programa, pelas oportunidades ímpares de ensino; e à Comissão de Pós-graduação, que me selecionou para receber o financiamento da CAPES/CNPq durante o curso.

Ao meu orientador, devo mais do que o apoio em todas as fases, e todas as viagens, que envolveram essa pesquisa. Devo a liberdade de expor minhas próprias ideias, mesmo quando não concordava com elas. Devo a oportunidade ímpar de participar de sua monitoria de graduação, que solidificou minha certeza de que lecionar é algo que desejo para a minha 
vida. Devo os valiosos conselhos que ajudaram a construir e refinar esse trabalho. Por tudo isso, e pela oportunidade de ingressar nesse programa, muitíssimo obrigada. 


\section{RESUMO}

Ana Beatriz Vanzoff Robalinho Cavalcanti. Mutação Constitucional: Origem, (Des)construção e Justificação. 2017. 162 f. Mestrado - Faculdade de Direito, Universidade de São Paulo, São Paulo, 2017.

As mudanças constitucionais são peças cada vez mais fundamentais no âmbito do dinâmico constitucionalismo moderno. A mutação constitucional é, nesse contexto, um conceito já familiar à esfera constitucional brasileira, mas a compreensão de sua real dimensão deixa a desejar. Nem as especificidades do (rico) processo de construção do conceito em sua origem fundamental à percepção do significado da mutação constitucional à época de seu surgimento - nem as circunstâncias e o conteúdo da desconstrução pela qual passou na segunda metade do Século XX, que afetou diretamente a adoção do conceito no Brasil, foram explorados com profundidade pela doutrina nacional. A exploração dessa história conceitual, no entanto, é necessária para responder duas dimensões de questionamentos acerca da mutação constitucional: o real significado do conceito e por consequência seu papel na teoria constitucional brasileira. As conclusões decorrentes da exploração desses questionamentos são surpreendentes e contraditórias. Por um lado, o conceito de mutação constitucional que vem sendo adotado no Brasil pouco tem em comum com o fenômeno descrito pela Escola Alemã de Direito Público na virada do Século XIX, e com maior razão se relaciona com o exaustivamente explorado campo da interpretação constitucional. Por outro, tal adoção parece ter trazido poucos benefícios para o processo de compreensão e desenvolvimento do fenômeno das mudanças constitucionais informais. A conclusão de que o conceito tradicional de mutação constitucional como o fenômeno das práticas contra-constitucionais, cunhado pela doutrina alemã no contexto do Império e da República de Weimar, melhor serviria o contexto fático e teórico da esfera constitucional brasileira leva à sugestão de uma revisão na aplicação do conceito no âmbito nacional. Mas o reconhecimento, e a nomeação, de um fenômeno constitucional nada implica em termos de sua valoração. A legitimação da mutação 
constitucional - um dos caminhos possíveis no tratamento do conceito - representa uma fase independente, que ganha uma faceta interessante através de teorias constitucionais que valorizam a expressão da soberania popular, por vezes em detrimento da formalidade positiva. Quer essa perspectiva venha a ser eventualmente adotada ou não, o objetivo maior é o estabelecimento de novas premissas no debate acerca da mutação constitucional.

Palavras chave: mutação constitucional; mudanças constitucionais informais; interpretação constitucional; práticas contra-constitucionais; legitimação. 


\section{ABSTRACT}

Ana Beatriz Vanzoff Robalinho Cavalcanti. Constitutional Mutation: Origins, (De)construction and Justification. 2017. 162 p. Masters - Faculty of Law, University of São Paulo, São Paulo, 2017.

Constitutional changes are increasingly fundamental implements in modern-day constitutionalism. Constitutional Mutation is, in this context, a familiar concept in the Brazilian constitutional sphere, but the grasp of its true dimension leaves something to be desired. Neither the specificities of the (rich) process of constructing the concept at its origin critical to apprehending the true meaning of constitutional mutation at the time it appeared or the circumstances and the content of the deconstruction it went through in the later half of the $20^{\text {th }}$ century, which directly affected the adoption of the concept in Brazil, were explored in depth by the national jurisprudence. The exploitation of this conceptual history, however, is necessary to answer two dimensions of questions regarding constitutional mutation: the true meaning of the concept and consequently its place Brazilian constitutional theory. The conclusions drawn from the exploring of these questions are surprising and contradictory. On the one hand, the concept of constitutional mutation that has been adopted in Brazil has little in common with the phenomenon of counter-constitutional practices described by the German School of Public Law in the turn of the $19^{\text {th }}$ century, and is more closely related to the exhaustively explored field of constitutional interpretation. On the other hand, such adoption seems to have brought little benefit to the process of comprehending and developing the phenomenon of informal constitutional changes. The conclusion that the traditional concept of constitutional mutation, forged by German jurisprudence in the context of the Empire and the Weimar Republic, would better serve the factual and theoretical context of the Brazilian constitutional sphere leads to the suggestion of a revision regarding the application of the concept in the national scope. But recognizing, and naming, a constitutional phenomenon 
means nothing in regards to its appraisal. The legitimation of constitutional mutation - one of the possible paths in handling the concept - represents an independent step, which acquires an interesting facet through constitutional theories that value the expression of popular sovereignty, often to the detriment of formalistic positivism. Whether this perspective is eventually adopted or not, the main goal is to establish new premises in the debate regarding constitutional mutation.

Keywords: constitutional mutation; informal constitutional changes; constitutional interpretation; counter-constitutional practices; legitimation. 


\section{SUMÁRIO}

INTRODUÇÃ

CAPÍtUlo I - ORIGEM: A ESCOLA ALEMÃ DE DIREITO PÚBLICO E A

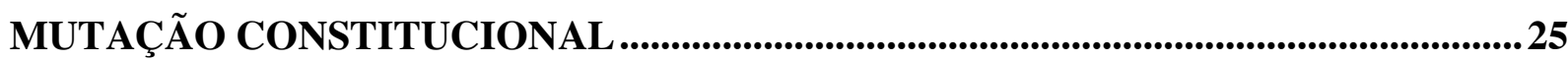

1. Considerações iniciais ............................................................................................................25

2. O contexto teórico do surgimento do conceito....................................................................26

3. A mutação constitucional no Império alemão .......................................................................34

3.1. O surgimento do termo mutação constitucional.............................................................36

3.2. O novo império e novas perspectivas................................................................. 41

4. A mutação constitucional na República de Weimar .............................................................46

4.1. A nova teoria constitucional e seus reflexos ..............................................................49

4.2. Organização e integração: perspectivas sobre a mutação ………………………….....56

4.3. A sistematização da teoria acerca da mutação ……………………………………......61

5. Um legado e o futuro .....................................................................................................................70

CAPÍTULO II - (DES)CONSTRUÇÃO: A MUTAÇÃO CONSTITUCIONAL COMO (RE)INTERPRETAÇÃO ............................................................................................76

1. O renascimento (e a reinvenção) de um conceito …………………………………………....76

2. Um novo conceito, em terras brasileiras ..................................................................................82

3. A prática constitucional brasileira ...........................................................................................93

3.1. Mutação constitucional como interpretação..............................................................94

3.2. Mutação constitucional como autêntica mudança da Constituição...............................98

4. Caminhos não percorridos: uma velha visão no mundo atual......................................... 107

5. Muito além da nomenclatura ..................................................................................................... 114

CAPÍTULO III - JUSTIFICAÇÃO: MUDANÇAS CONSTITUCIONAIS INFORMAIS

E SOBERANIA POPULAR .............................................................................................116 


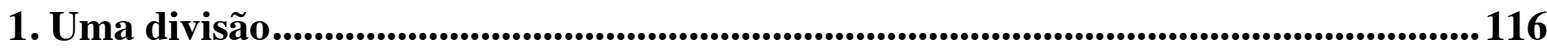

2. A voz do povo e seu poder constituinte ................................................................................118

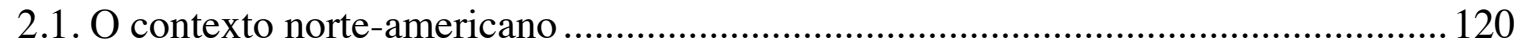

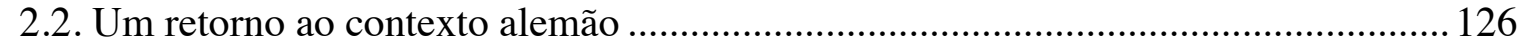

3. Mudanças informais e movimentos sociais ......................................................................129

3.1. O caso da Emenda XIV e a proteção dos direitos fundamentais .............................. 130

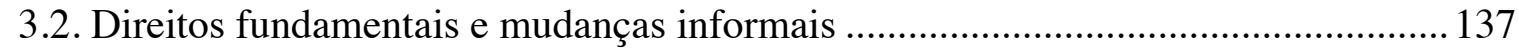

4. Mutação constitucional e a percepção da realidade social ............................................142

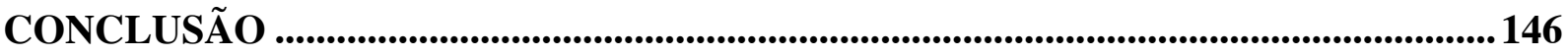

REFERÊNCIAS BIBLIOGRÁFICAS ...................................................................150 


\title{
INTRODUÇÃO
}

\author{
“'Quando eu uso uma palavra, ' disse Humpty Dumpty em um tom um tanto formal, \\ 'isto significa que eu escolho o que ela significa - nem mais nem menos.'. \\ 'A questão é,' disse Alice, 'se você pode fazer as palavras significarem tantas coisas \\ diferentes.'. 'A questão é,' disse Humpty Dumpty, 'quem é o chefe? - isso é tudo.,”'
}

Os dicionários de língua portuguesa conceituam mutação como "uma mudança de forma ou de essência"2 ou o "ato ou efeito de mudar-se"3. O termo também é, paradoxalmente, relacionado aos conceitos de inconstância "tendência ou facilidade para mudar de ideia, opinião, atitude" e de permanência "mudança genética que produz resultados permanentes" A mudança é um termo com infinitas conotações; no âmbito do direito constitucional está frequentemente relacionada a palavras como emenda, revisão e interpretação. A mutação acrescenta uma nova camada às possibilidades de mudança constitucional.

A vasta maioria da doutrina constitucional brasileira passou a conhecer do conceito jurídico de mutação constitucional na qualidade de tradução de um conceito de origem germânica. A expressão Verfassungswandlung, cunhada por Paul Laband em $1895^{6}$, vinha indicar uma mudança da Constituição que se diferenciava da reforma constitucional (Verfassungsänderung) por sua natureza informal. A própria tradução da expressão está longe de ser incontroversa. Na língua espanhola, Pablo Lucas Verdú famosamente traduziu o termo

\footnotetext{
${ }^{1}$ Lewis Carroll, em Alice Através do Espelho.

${ }^{2}$ FERREIRA, Aurélio Buarque de Holanda, Mutação, in: Novo Dicionário da Língua Portuguesa, [s.1.]: Nova Fronteira, 2000.

${ }^{3}$ Mutação, in: Dicionário Houaiss da Língua Portuguesa, Rio de Janeiro: Objetiva, 2001.

${ }^{4}$ Ibid.

${ }^{5}$ FERREIRA, Mutação.

${ }^{6}$ LABAND, Paul, Die Wandlungen der deutschen Reichsverfassung, Collections I Kyushu University Library, 1895.
} 
como mutación de la Constitución ${ }^{7}$; Na língua inglesa, Arthur Jacobson e Bernhard Schlink se utilizaram da expressão constitutional transformations para traduzir o termo do texto de Georg Jellinek $^{8}$. Nos Estados Unidos, em que tradicionalmente não se faz relação entre as mudanças constitucionais informais e a expressão formulada na doutrina alemã, aquelas são comumente referidas como informal constitutional amendments ${ }^{91011}$.

O vocabulário constitucional brasileiro já possuía familiaridade com algumas dessas expressões para além do conceito específico de mutação constitucional. Reforma e revisão são expressões frequentemente utilizadas no contexto das mudanças constitucionais, especialmente aquelas de natureza formal. No mais das vezes, ambos os conceitos designam processos de alteração constitucional positivados no próprio texto, diferenciando-se nos pormenores procedimentais e no grau das mudanças a serem efetivadas. $\mathrm{O}$ termo emenda designa o produto do processo legislativo que traduz a alteração realizada no texto; as emendas constitucionais são produtos do processo de reforma, e as emendas constitucionais de revisão produtos do processo de revisão constitucional ${ }^{1213}$.

Sob o prisma informal das mudanças constitucionais - aquelas que se efetivam sem a observância de um processo pré-desenhado pelo próprio texto constitucional - o conceito da interpretação constitucional se tornou familiar e crescentemente relevante, em geral combinado com expressões como construtiva ou evolutiva. Desse modo, a mudança

\footnotetext{
${ }^{7}$ Por exemplo, na tradução da obra de Hsü Dau-Lin em HSÜ, Dau-Lin, Mutación de la Constitución, Oñati: Instituto Vasco de Administración Pública, 1998.

${ }^{8}$ Em JELLINEK, Georg, Constitutional Amendment and Constitutional Transformation, in: JACOBSON, Arthur; SCHLINK, Bernhard, Weimar: A Jurisprudence of Crisis, Berkeley: University of California Press, 2002, p. 54 e ss.

${ }^{9}$ Por exemplo em LEVINSON, Sanford, Introduction: Imperfection and Amendability, in: LEVINSON, Sanford, Responding to Imperfection: The Theory and Practice of Constitutional Amendment, Princeton: Princeton University Press, 1995, p. 3 e ss.

${ }^{10}$ Ver também ACKeRmAN, Bruce, We the People, Volume 1: Foundations, Cambridge: Belknap Press, 1993 , p. 11 e ss.

${ }^{11}$ Sobre o uso dessa nomeclatura ver BALKIN, Jack M., Living Originalism, Cambridge: Belknap Press, 2014, p. 310 e ss.

${ }^{12}$ Sobre essa discussão terminológica no Brasil, ver FERREIRA FILHO, Manoel Gonçalves, Reforma, Revisão e Emenda Constitucional, no Direito Brasileiro, Revista de Direito Administrativo, n. 223, p. 53-74, 2001, p. 5455.

${ }^{13}$ Sobre o mesmo tema, ver também BARROSO, Luis Roberto, Curso de Direito Constitucional Contemporâneo, $4^{\text {a }}$. ed. São Paulo: Saraiva, 2013, p. 144 e ss.
} 
constitucional é compreendida como a mudança no sentido adotado da norma escrita no âmbito do processo de concretização daquela ${ }^{141516}$.

O vocábulo mutação, por sua vez, não obstante seu uso escasso no contexto constitucional brasileiro até décadas recentes, já poderia ser visto com alguma simpatia no papel de descritor de mudanças constitucionais dentre os que enxergavam o sistema constitucional - e por consequência o Estado por ele estabelecido - como um organismo, buscando apoio nas acepções biológicas do termo. Daí a relevância da colocação de Dalmo de Abreu Dallari, que em 1971 já aduzia que o intenso dinamismo social desafiava a ordem

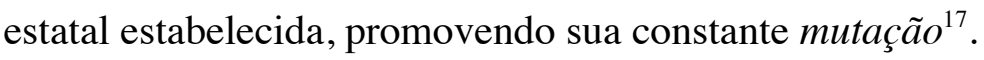

Nesse contexto, a introdução do termo mutação constitucional na esfera jurídica brasileira custou a se acomodar em meio a tal miríade de conceitos destinos a designar mudanças constitucionais, e como consequência seu posicionamento exato nesse conjunto doutrinário continua a gerar problemas. Não obstante a crescente relevância do termo no vocabulário constitucional pátrio, que atingiu, de fato, grandes proporções a partir da década de 2000, ainda é difícil precisar que sorte de mudanças constitucionais são descritas sob o âmbito do conceito de mutação constitucional. Essa confusão se reflete tanto na tentativa das fontes doutrinarias em determinar os exemplos da ocorrência da mutação constitucional no Brasil, que se mostra extremamente variada e raramente coincidente em sua totalidade, quanto no uso indiscriminado de termos distintos para designar um mesmo caso de alteração constitucional.

O julgamento da Reclamação n. 4335, do estado do Acre, pelo Supremo Tribunal Federal, inaugurou a era na qual o termo mutação constitucional se tornaria verdadeiramente familiar à jurisprudência constitucional brasileira. Naquele contexto, a discussão girava em torno do Art. 52, X, da Constituição Federal, que versa sobre o papel do Senado Federal no âmbito do controle judicial de constitucionalidade, e da eficácia das decisões do Supremo no

\footnotetext{
${ }^{14}$ Ibid., p. 129-138.

${ }^{15}$ BULOS, Uadi Lamêgo, Curso de Direito Constitucional, 9. ed. São Paulo: Saraiva, 2015, p. 446 e ss .

${ }^{16}$ SILVA, José Afonso da, Teoria do Conhecimento Constitucional, São Paulo: Malheiros Editores, 2014, p. 303-306.

${ }^{17} \mathrm{Na}$ edição original da obra. Ver em DALLARI, Dalmo de Abreu, Elementos da Teoria Geral do Estado, 33. ed. São Paulo: Saraiva, 2016, p. 138.
} 
exercício do controle difuso. A suposta mudança constitucional sobre a qual se digladiavam os Ministros foi descrita não apenas como uma mutação, mas por diversos outros termos, dentre os quais emenda, reinterpretação, interpretação ab-rogante, interpretação autêntica e interpretação criativa.

No âmbito do acórdão do julgamento da Arguição de Descumprimento de Preceito Fundamental n. 132, do Rio de Janeiro, passou-se a garantir o reconhecimento das uniões civis homossexuais nos mesmos termos do reconhecimento conferido às uniões heterossexuais, algo que, até então, não era permitido pelo ordenamento constitucional. Nesse contexto, também uma ampla coleção de termos foi utilizada para designar a classe de mudança constitucional efetivada naquela ocasião pelo tribunal: mutação, revisão, e interpretação em suas mais variadas formas - não-reducionista, analógica, legitimadora, correta, corretiva, aberta, sistemática e teleológica.

À doutrina não assistiu melhor sorte na tentativa de desvendar a real natureza dessas controversas mudanças constitucionais. Muitos autores as classificaram como autênticas mutações constitucionais; outros aduziram tratarem-se de meras reinterpretações do texto da Constituição, através das mais variadas técnicas; outros, ainda, foram além, chegando a equivaler tais mudanças a verdadeiras reformas constitucionais. A ausência de um consenso acerca da ocorrência da mutação constitucional, nesses e em diversos outros casos, é agravada pelo fato de que os limites do conceito parecem fluídos, e frequentemente se confundem com os de outros conceitos jurídicos, principalmente o da interpretação.

Uma breve análise do tratamento conferido à mutação constitucional pela doutrina e jurisprudência pátrias revela a necessidade de se pautar uma diferenciação clara entre os conceitos de interpretação e alteração da Constituição; o primeiro passo no sentido de elucidar o significado da mutação constitucional é melhor delinear essas fronteiras conceituais.

$\mathrm{Na}$ introdução da obra Responding to Imperfection $^{18}$, uma coleção acerca da teoria das mudanças constitucionais, Sanford Levinson observa que o sistema constitucional norteamericano foi o primeiro a ser concebido levando em consideração a possibilidade de mudanças, criando, assim, um mecanismo através do qual pudesse servir uma sociedade em

\footnotetext{
${ }^{18}$ LEVINSON, Introduction: Imperfection and Amendability.
} 
evolução e uma ferramenta para garantir sua própria existência continuada. Gordon Wood comparou essa construção inovadora com a institucionalização e legitimação da revolução ${ }^{19}$.

Levinson observa que as escrituras sagradas tradicionais podem permitir mudanças, mas não comportam o que ele chamará de emendas - mudanças que não estão disponíveis através de qualquer interpretação do texto e da estrutura existentes. Somente a Constituição que o autor logra comparar com textos sagrados das maneiras mais inventivas e surpreendentes ao longo de sua obra ${ }^{20}$ - comporta mudanças genuínas, acréscimos e decréscimos que alteram verdadeiramente o seu conteúdo.

A reivindicação de Levinson, assim, é de que tais mudanças são fundamentalmente distintas do resultado da interpretação de um texto, e como tais merecem um processo próprio de criação. Fundamentalmente, o autor distingue dois tipos de processos através dos quais as mudanças constitucionais se criam: o desenvolvimento ordinário pela interpretação e o desenvolvimento extraordinário por emenda ${ }^{21}$. Nesse sentido:

O contraste entre a interpretação e a emenda é na verdade parecido com aquele entre o desenvolvimento orgânico e a invenção de soluções inteiramente novas para velhos problemas. Nessa perspectiva, ‘interpretações’ estão ligadas de modo especificável a análises do texto ou ao menos do corpo de materiais convencionalmente compreendidos como no âmbito do constitucionalista comprometido. ${ }^{22}$

A emenda constitucional, na concepção apresentada, é uma invenção jurídica não derivável do corpo existente de materiais jurídicos aceitáveis. Descrever algo como uma

\footnotetext{
${ }^{19}$ LEVINSON, Sanford (Org.), Responding to Imperfection - The Theory and Practice of Constitutional Amendment, Princeton: Princeton University Press, 1995, p. 4.

${ }^{20}$ Ver, nesse sentido, LEVINSON, Sanford, Constitutional Faith, 2. ed. Princeton: Princeton University Press, 2011.

${ }^{21}$ É interessante, nesse sentido, a inversão da assunção instintiva de que o processo ordinário de mudança constitucional é aquele que se dá pela via formal, ao qual se dá, usualmente, o nome de emenda. Mas a lógica utilizada por Levinson aqui é distinta; ordinário e extraordinário são termos utilizados para descrever a natureza da mudança empreendida, e não o processo pelo qual se concretizou. Nesse sentido, as mudanças ordinárias são aquelas que ocorrem nos limites estabelecidos pelo texto existente, e as extraordinárias são aquelas que requerem que se vá além. LEVINSON, Sanford, How Many Times has the Unites States Constitution been Amended? (A) < 26; (B) 26; (C) 27; (D) > 27: Accounting for Constitutional Change, in: LEVINSON, Sanford (Org.), Responding to Imperfection: The Theory and Practice of Constitutional Amendment, Princeton: Princeton University Press, 1995, p. 14.

${ }^{22}$ Ibid., p. 15, Tradução nossa.
} 
emenda é proclamar sua ilegitimidade enquanto uma interpretação ${ }^{23}$. No entanto, enquanto a interpretação carrega consigo uma presunção de legalidade, uma autoridade, uma emenda ainda deve, de alguma forma, adquirir aceitabilidade e autoridade legal. O modo lógico e tradicional de adquirir essa autoridade é seguindo o processo formal para emenda disposto na própria Constituição.

Se o argumento é de que é possível entender a interpretação como uma limitação à emenda - se algo pode ser interpretado, não precisa ser emendado - como podem ser definidos os limites da própria interpretação? O assunto é complexo, tendo sido objeto do mais diversos debates acadêmicos. A tentativa de Levinson, no entanto, é de fornecer um conceito ao mesmo tempo amplo e simples. O autor aduz que a interpretação não é o que pode ser feito logicamente com a linguagem, mas o que pode ser aceito pela comunidade jurídica como "onthe-wall"24 - uma derivação crível do corpo jurídico existente ${ }^{25}$.

$\mathrm{O}$ autor afirma que é preciso aceitar que nem tudo pode ser legitimamente inferido a todo e qualquer momento do material jurídico pré-existente - ao menos se aquele que está interpretando deseja permanecer membro de uma comunidade de intérpretes ${ }^{2627}$. Mas essa conceituação nada diz a respeito do grau de mudança que está sendo implementada. Consequências notadamente significativas podem partir da interpretação da Constituição especialmente quando as cláusulas interpretadas são abertas, e pouco limitam o intérprete. No

\footnotetext{
${ }^{23}$ Ibid., p. 17.

24 "On-the-wall" e "off-the-wall" são conceitos famosamente desenvolvidos por Jack Balkin para diferenciar argumentos jurídicos que são amplamente aceitos como plausíveis pela comunidade - mesmo que não haja consenso sobre o seu conteúdo - em um dado momento, e argumentos jurídicos que não são. O autor explica que os conceitos de "on-the-wall" e "off-the-wall" não são fixos no tempo. O que é "off-the-wall" em um momento pode se tornar "on-the-wall" no momento seguinte, através da litigância militante ou da adoção de um argumento pela maioria da Suprema Corte, por exemplo. Balkin frequentemente usa o exemplo da interpretação conferida à commerce clause da Constituição no caso Obamacare, que se mostrava absolutamente desconhecida para a comunidade jurídica antes de o Chief Justice Roberts utiliza-la para limitar o alcance do programa. BALKIN, Living Originalism, p. 18 e ss.

${ }^{25}$ LEVINSON, How Many Times has the Unites States Constitution been Amended?, p. 18.

${ }^{26}$ Assim como Levinson, o alemão Peter Häberle acredita na necessidade da formação de uma comunidade de intérpretes, e observa que a efetividade da empreitada depende da manutenção de canais de comunicação abertos entre os intérpretes - o que em outras palavras significa que todos precisam falar a mesma língua para que a colaboração funcione. HÄBERLE, Peter, Hermenêutica Constitucional - A Sociedade Aberta Dos Interpretes Da Constituição: contribuição para a interpretação plutalista e "procedimental" da Constituição, Porto Alegre: Sergio Antonio Fabris Editor, 1997, p. 41 e ss.

${ }^{27}$ Sobre a interpretação constitucional protestante e a visão de Levinson sobre a comunidade de intérpretes constitucionais, ver LEVINSON, Constitutional Faith, p. 10 e ss.
} 
mesmo sentido, mudanças genuínas, que aqui tem sido chamadas de emendas, podem ser amplas ou estreitas, especialmente quando o que se está medindo é o impacto no mundo real. Tanto mudanças grandes e significativas como pequenas e triviais podem ocorrer através de dois canais: ordinárias através da interpretação e extraordinárias através de emendas.

Nesse sentido considere-se, por uma lado, a discussão apresentada por Levinson acerca de quantas vezes a Constituição dos Estados Unidos foi emendada. Vinte e sete emendas formais foram acrescidas ao texto original desde o século XVIII; mas, aplicando sua conceituação, o autor conclui que a Constituição foi emendada menos de vinte e seis vezes. A análise das adições textuais revela que várias delas - senão a maioria - não representaram invenções jurídicas genuínas, mas explicações ou reafirmações de cláusulas que poderiam ser, de fato, inferidas através da interpretação do texto existente.

É o caso das Emendas XV e XIX, que garantem respectivamente o acesso ao voto dos negros e das mulheres - direitos que poderiam ser inferidos e que certamente decorrem das afirmações sobre cidadania e igualdade contidas na Emenda XIV; E da Emenda X, que reafirma a natureza enumerada e limitada dos poderes da União, e a natureza plenária dos poderes dos estados - a própria essência do constitucionalismo americano em sua fundação, e um principio que pode ser inferido de todas as construções dispostas no texto original ${ }^{28}$.

Considere-se, por outro lado, a análise de Bruce Ackerman da Revolução dos Direitos Civis como um momento constitucional. Ackerman argumentará que os chamado superstatues e super-precedents da era dos direitos civis efetivaram genuínas mudanças na ordem constitucional - criando proposições que não podem ser inferidas da ordem constitucional existente $^{29}$. Nesse sentido, esses desenvolvimentos constitucionais devem ser considerados emendas, e não interpretações, pelos critérios expostos por Levinson, mesmo que não tenha sido adicionados ao corpo existente de leis constitucionais pelo processo formal de emenda.

Esses debates sugerem que não apenas as verdadeiras alterações da Constituição podem ser formais e informais, mas também que as adições formais ao texto da Constituição podem ser verdadeiras alterações ou não. De modo mais relevante, sugerem que os conceitos

\footnotetext{
${ }^{28}$ LEVINSON, How Many Times has the Unites States Constitution been Amended?, p. 29-31.

${ }^{29}$ ACKerman, Bruce, We the People, Volume 3: The Civil Rights Revolution, Cambridge: Belknap Press, 2014, p. 11 e ss.
} 
de alteração e interpretação são fundamentalmente distintos, mas não se prendem às amarras de formalidade e informalidade, respectivamente, no modo tradicionalmente sugerido pela doutrina brasileira que trata do tema. E esse ponto influirá diretamente sobre a tentativa de diferenciar os conceitos de mutação e interpretação, e consequentemente de delimitar o real alcance da mutação constitucional.

Nesse sentido, apesar da familiaridade do conceito no âmbito da esfera constitucional brasileira, a real dimensão de seu significado carece de uma exploração mais aprofundada. A doutrina invariavelmente remete a origem do termo ao contexto da Alemanha na virada do século XX, e mais precisamente aos escritos de Laband e de Georg Jellinek. Também é comum a remissão à doutrina de Konrad Hesse, que explorou o conceito muitas décadas depois, no âmbito da República Federal da Alemanha. No entanto, a contribuição desses autores pouco é explorada para além da extração de um conceito para a mutação constitucional. E nem sempre é notado que o conceito tradicional cunhado no século XIX e conceito formulado por Hesse em meados da década de 1970 não possuem o mesmo conteúdo.

Em verdade, entre as análises dos positivistas do Império alemão na virada do século e de autores modernos como Hesse e Peter Häberle várias décadas depois, se localiza um período histórico em que o conceito de mutação constitucional foi amplamente explorado e desenvolvido: os turbulentos anos da República de Weimar. Nesse contexto grandes constitucionalistas como Rudolf Smend e Hermann Heller também se debruçaram sobre o conceito, e um discípulo de Smend, o chinês Hsü Dau-Lin, produziu uma completa tese sobre a mutação constitucional.

Todo esse corpo teórico não prescinde de uma análise organizada, sem a qual não será possível compreender a fundo o fenômeno que se encaixa na descrição do termo, e suas repercussões para o sistema constitucional. Nesse sentido, o primeiro capítulo será dedicado à análise do processo acadêmico que gerou o conceito de mutação constitucional. O desenvolvimento do conceito por grandes nomes da Escola Alemã de Direito Público será contextualizado no ambiente jurídico, político e social em que ocorreu.

Com vistas a esse objetivo, serão analisadas as bases teóricas que permearam o estudo do direito constitucional no âmbito do Império alemão estabelecido em 1871 e na República de Weimar, que durou de 1919 até a desintegração do sistema pela ascensão do nazismo. Ao 
final, a tentativa será no sentido de compreender o legado deixado por esse rico corpo doutrinário, definindo com clareza o conceito de mutação constitucional para a doutrina tradicional.

A análise do tratamento conferido pela doutrina Alemã moderna ao conceito especialmente na obra de Konrad Hesse - será realizada já no segundo capítulo. O objetivo inicial será o de demonstrar o que foi feito da herança deixada pela doutrina do Pré-Guerra. Rapidamente fica claro que o advento de um novo e amplamente distinto sistema constitucional, calcado em um novo contexto político e social, a doutrina alemã optou por abandonar o conceito tradicional de mutação constitucional e apropriar-se do termo para descrever um novo fenômeno.

Essa constatação é essencial porque foi o conceito moderno de mutação constitucional que logrou encontrar espaço em terras brasileiras. Na seção seguinte, será analisada a recepção do conceito de mutação constitucional pela doutrina nacional, verificando-se a prevalente influencia dos doutrinadores modernos do direito germânico, por vias diretas e indiretas. Em seguida partir-se-á à análise da jurisprudência constitucional brasileira - a partir da compilação de casos baseada na sugestão de doutrinadores nacionais, será demonstrada a profundidade da confusão criada pelos teóricos entre os conceitos de mutação constitucional e sua aplicação.

A partir desses estudos de caso serão analisadas duas questões: primeiro, em que medida o conceito de mutação constitucional adotado pela doutrina brasileira auxilia na resolução de problemas constitucionais concretos; e segundo, se há mais de um fenômeno distinto frequentemente tratado pela doutrina nacional sob o âmbito da mutação constitucional - e nesse caso, como lidar com a parcela de repercussões fáticas da realidade constitucional que resta descontextualizada no âmbito teórico.

O terceiro capítulo consistirá em um exercício distinto. Serão desenvolvidos ali argumentos destinados a justificar a ocorrência da mutação constitucional, caracterizando-a como um instrumento legítimo de alteração da Constituição. Nesse contexto serão exploradas a teoria e a prática norte-americanas relacionadas às mudanças constitucionais informais, que em seu território conheceram maior desenvolvimento do que em qualquer outra democracia moderna. 
Será demonstrado que as dificuldades intrínsecas produzidas pelo dificultoso processo formal de alteração constitucional previsto no Artigo V da Constituição americana levaram ao desenvolvimento de uma prática recorrente de mudanças constitucionais informais, que se tornaram a regra do desenvolvimento constitucional naquele contexto a partir do século XX. Nesse contexto, constitucionalistas se viram obrigados a buscar soluções que não resultassem na invalidação de todas as conquistas constitucionais relevantes ocorridas no último século. $\mathrm{O}$ resultado desse exercício se revela uma preciosa compreensão das relações entre a necessária atualização do conteúdo constitucional e os anseios sociais que perpassam tentativas formalistas de serem transformados em normas constitucionais.

Por fim, no âmago desse trabalho está um exercício de compreensão: a análise da doutrina constitucional alemã da mutação constitucional - tradicional e moderna - se une à exploração da doutrina e jurisprudência brasileiras para determinar quais conceitos jurídicos se referem a quais fenômenos de nossa realidade constitucional. A sugestão que se segue é justificada, mas é apenas uma sugestão: ver reconhecida a existência do fenômeno das autenticas mudanças constitucionais informais na esfera constitucional pátria já seria suficiente.

No exercício seguinte se localiza menos uma sugestão e mais um vislumbre: uma porta a partir da qual podem ser distinguidas possibilidades futuras. Ao reconhecimento do fenômeno da mutação constitucional (em sua acepção tradicional) se seguem o questionamentos sobre as consequências, e a conveniência, de sua existência. Nesse contexto a doutrina cumpre seu papel de questionar e imaginar. Esse exercício de imaginação vislumbra um futuro aprimorado para a jurisdição constitucional brasileira. 


\section{CONCLUSÃO}

"É necessário sair da ilha para ver a ilha, não nos vemos se não saímos de nós. „380

Antes de tudo, esse trabalho foi um exercício de como olhar para dentro. O uso do direito comparado pode ser uma ferramenta poderosa para a melhor compreensão do sistema jurídico, seus limites e suas possibilidades. Na era da ascensão do constitucionalismo mundial - para usar mais uma expressão ackermaniana - seria dispendioso ao extremo prescindir da experiência de outros sistemas, e perder a oportunidade de estudar seus erros e seus triunfos, apreendendo como problemas similares aos enfrentados pela nossa realidade constitucional foram superados.

Mas encontrar o tom certo para fazer uso dessas experiências distintas não é tarefa fácil. O direito constitucional brasileiro há muito tem sofrido as consequências dos equívocos envolvidos na transposição descontextualizada de conceitos estrangeiros para sua realidade. Não compreendemos o uso do direito comparado como uma ferramenta que nos permite melhor enxergar nossa própria realidade; olhamos para fora e não para dentro. Em muitos aspectos, aí está o cerne do problema com o tratamento que vem sido conferido à mutação constitucional.

Nesse sentido, estudar a fundo a gênese do conceito se mostrou tarefa essencial - a necessidade é a mãe da invenção. Somente através da compreensão do contexto político, jurídico e social que impulsionou doutrinadores alemães da virada do século XX a cunharem um termo destinado a descrever o fenômeno das mudanças constitucionais informais foi possível apreender o verdadeiro alcance do conceito. O mesmo poderiam ser dito da análise do tratamento conferido por doutrinadores alemães modernos ao termo. Uma nova cultura jurídica foi responsável pela decisão de abandonar o conceito original e cunhar a descrição de

\footnotetext{
${ }^{380}$ José Saramago, em Ensaio Sobre a Cegueira.
} 
um novo fenômeno jurídico. Esses estudiosos tomaram a decisão consciente de adotar um conceito que lhes parecera útil na resolução de problemas jurídicos concretos. Podemos dizer que adotamos o mesmo discernimento ao adotar o conceito moderno de mutação constitucional na esfera jurídica brasileira?

A primeira contribuição do trabalho se fez por essas linhas: (i) a diferenciação, por um lado, entre os conceitos tradicional e moderno - como convencionamos chama-los - de mutação constitucional, cada qual vinculado a um momento histórico, a um arcabouço teórico e a um corpo doutrinário próprios; e por outro, entre os conceitos de mudança constitucional e interpretação. Somente através dessas diferenciações é possível refletir de forma esclarecida sobre os méritos e ônus de adotar uma ou outra vertente doutrinaria da mutação constitucional.

De fato, a análise da jurisprudência constitucional reascendeu o debate entre emenda e interpretação. O desconforto com a extensão de algumas decisões atribuídas ao Supremo Tribunal Federal, conforme se verificou, não carece de fundamento. O que existe é um notável nível de confusão entre o permitido e o não permitido, entre o interpretado e o verdadeiramente alterado. Mesmo quando essa questão resta esclarecida, percebe-se que o tratamento adotado pela doutrina não tem muito a acrescentar nem a um grupo de casos, nem ao outro.

Assim, a lembrança da doutrina constitucional alemã sugere um novo exercício; uma nova transposição, pautada pela necessidade de nossa realidade constitucional. A necessidade de compreender as instâncias em que a constituição é efetivamente alterada por canais informais está presente, e a doutrina nacional não oferece possibilidades concretas para suprila. Mais um uso para o direito comparado se revela: outros sistemas fizeram essa escolha diante da mesma necessidade. Se não por outro motivo, a análise daquela transposição demonstra que é possível adaptar um conceito de outra era ao constitucionalismo moderno.

A segunda contribuição do trabalho se resume nessa sugestão: (ii) o retorno à doutrina e ao conceito tradicionais de mutação constitucional, não apenas pela inadequação observada na adoção do conceito moderno, mas também pelos benefícios que essa adoção traria ao desenvolvimento teórico e à compreensão prática da esfera constitucional brasileira.

Qual seria a face dessa mutação constitucional entre nós? A pergunta permeia as recorrentes conceituações e classificações sugeridas ao longo do texto. A imposição da 
realidade sobre a norma, o fenômeno fático que se transmuta em fenômeno jurídico, depende a um só tempo de atos conscientes e inconscientes. Os primeiros estabelecem a prática inconstitucional; os segundos as reconhecem como tais, e em reconhece-las não as rejeitam. A facilidade com as emendas constitucionais formais de concretizam em nosso sistema sugerem que o legislativo seria um canal menos comum para a concretização de práticas inconstitucionais do que se verificou em outros sistemas. A preocupação do judiciário com sua própria reputação sugere que ali o reconhecimento será custoso. Em todos os casos, a mudança se torna mais confortável quando um poder reconhece a aquiescência do outro.

O sistema brasileiro já foi palco de todas as práticas sugeridas. Existe, na dinamicidade de nosso sistema, o potencial de comportar diferentes instrumentos de concretização das mudanças constitucionais informais. As mutações constitucionais autênticas parecem viáveis; mas seriam também desejáveis? Esse questionamento, separado e independente, não implica, por sua resposta negativa, o abandono da transposição proposta. Para criticar é preciso compreensão; um fenômeno sem nome e sem limites delineados não pode ser combatido. Mas a escolha aqui não foi a de combater. Na seleção entre dois caminhos, escolheu-se buscar justificações para o fenômeno da mutação constitucional.

Mais uma vez se utilizou da experiência comparada. A experiência constitucional norte-americana é regida pelas mudanças constitucionais informais. Há muito aquele sistema assegura sua sobrevivência e atualização através de caminhos alternativos ao processo formal de emenda. Ali também estão presentes insurgências e críticas. Mas uma parcela da doutrina encontrou maior valor na tentativa de compreender o fenômeno das emendas constitucionais informais como uma consequência da própria natureza do sistema estabelecido pela Constituição.

Tratava-se ali de uma questão de sobrevivência: descobrir as mudanças constitucionais informais como ilegítimas seria condenar o sistema constitucional como um todo, tamanha sua presença nos dias atuais. No entanto, em realidade no âmbito da busca por justificativas a doutrina norte-americana redescobriu a razão de ser da evolução constitucional, e encontrou mais um modo de reafirmar a soberania popular. Se o poder constituinte pertence ao povo, esse pode escolher como exerce-lo, dentro ou fora das amarras formais. A conexão foi criada entre as mudanças constitucionais informais e a expressão da vontade popular, através dos 
mais diversos canais, que podem se utilizar em maior ou menor grau das instituições do estado. De importância fundamental no processo estava apenas a manutenção aberta do canal que termina por transubstanciar a vontade popular em lei constitucional.

A transposição dessas ideias ao ordenamento jurídico pátrio pode ser o maior dos desafios apresentados, mas tampouco se sugere que os instrumentos empregados pela doutrina estudada, tão específicos à realidade constitucional norte-americana, sejam reproduzidos no todo ou em parte. O que se pode retirar da análise daquela experiência são possibilidades para novas formas de atualização - e assim, de supervivência - do sistema constitucional.

Dessa feita, a terceira contribuição do trabalho está fundada nessa tentativa: (iii) o oferecimento de uma rota para a justificação do fenômeno da mutação constitucional, em homenagem ao princípio da soberania popular que permeia nosso sistema constitucional.

Entretanto, por mais que o trabalho procure persuadir a doutrina constitucional brasileira do valor dessas experiências, é preciso reiterar que delas não depende o sucesso da empreitada. Se o fenômeno das autenticas mudanças constitucionais informais for reconhecido como parte integrante da realidade constitucional brasileira, o objetivo terá sido atingido. Os méritos da transposição da doutrina alemã tradicional, para utilizar o termo mutação constitucional na descrição do fenômeno, foram apresentados. Acredita-se que ela pode trazer benefícios reais ao debate; mas ninguém pode determinar o futuro da doutrina constitucional sozinho.

Se a academia e a prática jurídicas se engajarem no debate acerca da legitimidade da mutação constitucional, essa conversa já será uma contribuição muito mais significativa para o futuro desenvolvimento de nosso sistema jurídico do que aquelas que até agora envolveram o conceito. Cabe a nós enfrentar as mutações constitucionais por seus próprios méritos, apreendendo o lugar que ocupam na estrutura criada pela Constituição, e não disfarçar as práticas inconstitucionais como se sua mera existência pudesse levar nosso sistema à ruína. Ele estará seguro enquanto formos capazes de entender onde pisamos. Não existem prescrições fixas no direito constitucional; ele é o que fazemos dele. 


\section{REFERÊNCIAS BIBLIOGRÁFICAS}

Obras:

ACKERMAN, Bruce. Constitutional Politics/Constitutional Law. The Yale Law Journal, v. 99, n. 3, p. 453-547, 1989.

ACKERMAN, Bruce. Higher Lawmaking. In: LEVINSON, Sanford (Org.). Responding to Imperfection: the theory and practice of constitucional amendment. Princeton: Princeton University Press, 1995, p. 63-88.

ACKERMAN, Bruce. The Living Constitution. Harvard Law Review, v. 120, n. 7, p. 1737-1812, 2007.

ACKERMAN, Bruce. The Rise of World Constitutionalism. Virginia Law Review, v. 83, n. 4, p. 771-797, 1997.

ACKeRman, Bruce. We the People, Volume 1: Foundations. Cambridge: Belknap Press, 1993.

ACKERMAN, Bruce. We the People: Volume 2: Transformations. Cambridge: Belknap Press, 2000.

ACKERMAN, Bruce. We the People, Volume 3: The Civil Rights Revolution. Cambridge: Belknap Press, 2014.

ALBERT, Richard. Constitutional Handcuffs. Arizona State Law Journal, v. 42, p. 663, 2010. 
AMAR, Akhil Reed. America's Constitution: A Biography. Nova York: Random House, 2006.

AMAR, Akhil Reed. Philadelphia Revisited: Amending the Constitution outside Article V. The University of Chicago Law Review, v. 55, n. 4, p. 1043-1104, 1988.

AMARAL JÚNIOR, José Levi Mello do. Sobre a organização de poderes em Montesquieu: comentários ao Capítulo VI do Livro XI de O Espírito das Leis. Revista dos Tribunais, São Paulo, v. 868, p. 53-68, 2008.

ARATO, Andrew. Carl Schmitt and the Revival of the Doctrine of the Constituent Power in the United States. Cardozo Law Review, v. 21, p. 1739, 1999.

BALKIN, Jack M. Bruce 3.0. Balkinization. Disponível em: <http://balkin.blogspot.com/2014/05/bruce-30.html>. Acesso em: 19 nov. 2016.

BALKIN, Jack M. Living Originalism. Cambridge: Belknap Press, 2014.

BALKIN, Jack M.; LEVINSON, Sanford. Understanding the Constitutional Revolution. Virginia Law Review, p. 1045-1109, 2001.

BARROSO, Luis Roberto. Curso de Direito Constitucional Contemporâneo. $4^{\text {a }}$. ed. São Paulo: Saraiva, 2013.

BELLAMY, Richard; CASTIGLIONE, Dario. Constitutionalism and Democracy - Political Theory and the American Constitution. British Journal of Political Science, v. 27, n. 4, p. 595-618, 1997. 
BOBBITT, Philip. Constitutional Fate: Theory of the Constitution. Nova York: Oxford University Press, 1984.

BOBBITT, Philip. Is Law Politics? Stanford Law Review, v. 41, n. 5, p. 1233-1312, 1989.

BÖCKENFÖRDE, Ernst Wolfgang. Estudios sobre el Estado de Derecho y la democracia. Trad. Rafael de Agapito Serrano. [s.1.]: Trotta Editorial, 2000.

BONAVIDES, Paulo. Curso de Direito Constitucional. São Paulo: Malheiros Editores, 2014.

BREST, Paul et al. Processes of Constitutional Decisionmaking. Nova York: Wolters Kluwer Law \& Business, 2014.

BREST, Paul et al. Processes of Constitutional Decisionmaking: 2015 Supplement. Nova York: Wolters Kluwer Law \& Business, 2015.

BUlOS, Uadi Lamêgo. Curso de Direito Constitucional. 9. ed. São Paulo: Saraiva, 2015.

BULOS, Uadi Lamêgo. Da Reforma à Mutação da Constituição. Revista de Informação Legislativa, v. 33, n. 129, p. 25-43, 1996.

CALDWELL, Peter C. Popular Sovereignty and the Crisis of German Constitutional Law: The Theory and Practice of Weimar Constitutionalism. Durham: Duke University Press Books, 1997.

CANOtilho, José Joaquim Gomes. Direito Constitucional e Teoria da Constituição. $7^{\text {a }}$ ed. Coimbra: Almedina, 2007. 
CERF, Barry. Alsace-Lorraine since 1870. Nova York: The Macmillan, 1919. Disponível em: <http://archive.org/details/alsacelorraines00cerfgoog>. Acesso em: 23 nov. 2016.

COVER, Robert M. Foreword: Nomos and Narrative. Harvard Law Review, v. 97, p. 68, 1983.

DALLARI, Dalmo de Abreu. Elementos da Teoria Geral do Estado. 33. ed. São Paulo: Saraiva, 2016.

ELKINS, Zachary; GINSBURG, Tom; MELTON, James. The Endurance of National Constitutions. Cambridge: Cambridge University Press, 2009.

ELY, John Hart. Democracy and Distrust: A Theory of Judicial Review. Cambridge: Harvard University Press, 1980.

ESKRIDGE, William N.; FEREJOHN, John. Super-statutes. Duke Law Journal, v. 50, n. 5 , p. 1215-1276, 2001 .

FERNANDES, Bernardo Gonçalves. Curso de Direito Constitucional. Salvador: Juspodivum, 2014.

FERRAZ, Anna Cândida da Cunha. Processos Informais de Mudança da Constituição: mutações constitucionais e mutações inconstitucionais. [s.1.]: Max Limonad, 1986. (Série Jurídica Max Limonad, 1).

FERREIRA, Aurélio Buarque de Holanda. Mutação. In: Novo Dicionário da Língua Portuguesa. [s.1.]: Nova Fronteira, 2000. 
FERREIRA FILHO, Manoel Gonçalves. Da validade e legitimidade das mutações constitucionais. In: MENDES, Gilmar Ferreira; MORAIS, Carlos Blanco de (Orgs.). Mutações Constitucionais. São Paulo: Saraiva, 2016, p. 327-331. (Série IDP/Saraiva).

FERREIRA FILHO, Manoel Gonçalves. Reforma, Revisão e Emenda Constitucional, no Direito Brasileiro. Revista de Direito Administrativo, n. 223, p. 53-74, 2001.

GREENHOUSE, Linda; SIEGEL, Reva B. Before (and After) Roe v. Wade: New Questions About Backlash. The Yale Law Journal, p. 2028-2087, 2011.

HÄBERLE, Peter. Hermenêutica Constitucional - A Sociedade Aberta Dos Interpretes Da Constituição: contribuição para a interpretação plutalista e "procedimental" da Constituição. Trad. Gilmar Ferreira Mendes. Porto Alegre: Sergio Antonio Fabris Editor, 1997.

HAILBRONNER, Michaela. Rethinking the rise of the German Constitutional Court: From anti-Nazism to value formalism. International Journal of Constitutional Law, v. 12, n. 3, p. 626-649, 2014.

HAMILTON, Alexander; MADISON, James; JAY, John. The Federalist. Indianapolis: Hackett Publishing Company, 2005.

HART, H. L. A. The Concept of Law. Oxford: Oxford University Press, 2012.

HARTMANN, Bernd. The Arrival of Judicial Review in Germany Under the Weimar Constitution of 1919. Brigham Young University Journal of Public Law, v. 18, n. 1, p. 107-130, 2003. 
HELLER, Hermann. The Essence and Structure of the State. In: JACOBSON, Arthur; SCHLINK, Bernhard. Weimar: A Jurisprudence of Crisis. Berkeley: University of California Press, 2002, p. 265-279.

HESSE, Konrad. Grenzen der Verfassungswandlung. In: EHMKE, Horst et al. Festschrift für Ulrich Scheuner zum 70. Geburtstag. Berlim: Duncker \& Humblot, 1973, p. 123141.

HESSE, Konrad. Limites da Mutação Constitucional. In: Temas Fundamentais do Direito Constitucional. Trad. Inocêncio Mártires Coelho. São Paulo: Saraiva, 2009, p. 147-171. (Série IDP/Saraiva).

HSÜ, Dau-Lin. Mutación de la Constitución. Oñati: Instituto Vasco de Administración Pública, 1998.

JACOBSON, Arthur; SCHLINK, Bernhard (Orgs.). Weimar: A Jurisprudence of Crisis. Berkeley: University of California Press, 2002.

JELLINEK, Georg. Constitutional Amendment and Constitutional Transformation. In: JACOBSON, Arthur; SCHLINK, Bernhard. Weimar: A Jurisprudence of Crisis. Berkeley: University of California Press, 2002, p. 54-57.

JELLINEK, Georg. Reforma y Mutación de la Constitución. Trad. Christian Förter. Madrid: Centro de Estudios Constitucionales, 1991. Disponível em: <http://dialnet.unirioja.es/servlet/libro?codigo=63067>. Acesso em: 5 nov. 2015.

JELLINEK, Georg. Verfassungsänderung und Verfassungswandelung: Eine staatsrechtlich-politische Abhandlung. Berlim: Häring, 1906. 
KALYVAS, Andreas. Democracy and the Politics of the Extraordinary: Max Weber, Carl Schmitt, and Hannah Arendt. Cambridge: Cambridge University Press, 2009.

KELSEN, Hans. Quem deve ser o guardião da Constituição? In: KELSEN, Hans. Jurisdição Constitucional. São Paulo: Martins Fontes, 2013, p. 239-292.

KELSEN, Hans. Teoria Geral do Direito e do Estado. Trad. Luis Carlos Borges. São Paulo: Martins Fontes, 2000.

KELSEN, Hans. Teoria Pura do Direito. Trad. João Baptista Machado. 8a. ed. São Paulo: Martins Fontes, 2009.

KELSEN, Hans. Wer soll der Hünter der Verfassung sein? In: KLECATSKY, Hans; MARCIC, Rene; SCHAMBECK, Herbert (Orgs.). Die Wiener rechtstheoretische Schule. Viena: Europa-Verlag, 1968, p. 1873-1922.

KLARMAN, Michael J. Constitutional Fact/Constitutional Fiction: A Critique of Bruce Ackerman's Theory of Constitutional Moments. Stanford Law Review, v. 44, n. 3, p. 759-797, 1992.

KOMMERS, Donald P.; MILLER, Russell A. The Constitutional Jurisprudence of the Federal Republic of Germany. Durham: Duke University Press Books, 2012.

LABAND, Paul. Das Staatsrecht des Deutschen Reiches. 1. ed. Tübingen: H. Laupp, $1876.3 \mathrm{v}$.

LABAND, Paul. Die geschichtliche Entwicklung der Reichsverfassung seit der Reichsgründung. Tübingen: J.C.B. Mohr, 1907. 
LABAND, Paul. Die Wandlungen der deutschen Reichsverfassung. Collections I Kyushu University Library, 1895. Disponível em: <http:/hdl.handle.net/2324/1000130530>. Acesso em: 22 nov. 2016.

LABAND, Paul. Die Wandlungen der deutschen Reichsverfassung (Vortrag gehalten in der Gehe-Stiftung zu Dresden am 16. März 1895). Collections I Kyushu University Library. Disponível em: <http://hdl.handle.net/2324/1000130530>. Acesso em: 22 nov. 2016.

LABAND, Paul. Le Droit Public de l'Empire Allemand, v. 2. Paris: V. Giard \& E. Brière, 1901.

LEVINSON, Sanford. Constitutional Faith. 2. ed. Princeton: Princeton University Press, 2011.

LEVINSON, Sanford. How Many Times has the Unites States Constitution been Amended? (A) < 26; (B) 26; (C) 27; (D) > 27: Accounting for Constitutional Change. In: LEVINSON, Sanford (Org.). Responding to Imperfection: The Theory and Practice of Constitutional Amendment. Princeton: Princeton University Press, 1995, p. 13-36.

LEVINSON, Sanford. Introduction: Imperfection and Amendability. In: LEVINSON, Sanford. Responding to Imperfection: The Theory and Practice of Constitutional Amendment. Princeton: Princeton University Press, 1995, p. 3-12.

LEVINSON, Sanford. Popular Sovereignty and the United States Constitution: Tensions in the Ackermanian Program. Yale Law Journal, v. 123, p. 2644, 2013.

LEVINSON, Sanford (Org.). Responding to Imperfection - The Theory and Practice of Constitutional Amendment. Princeton: Princeton University Press, 1995. 
LEVINSON, Sanford; BALKIN, Jack M. Constitutional Crises. University of Pennsylvania Law Review, v. 157, n. 3, p. 707-753, 2009.

LOEWENSTEIN, Karl. Teoría de la Constitución. Barcelona: Ariel, 1979.

LOEWENSTEIN, Karl. Verfassungsrecht und Verfassungspraxis der Vereinigten Staaten. Heidelberg: Springer-Verlag, 1959.

MAIA, Paulo Sávio N. Peixoto. O guardião da Constituição na polêmica KelsenSchmitt: Rechtsstaat como referência semântica na memória de Weimar. Dissertação de Mestrado, UnB, Brasília, 2007. Disponível em: <http://repositorio.unb.br/handle/10482/3525>. Acesso em: 11 dez. 2016.

MENDES, Gilmar Ferreira. Limite entre interpretação e mutação: análise sob a ótica da jurisdição constitucional brasileira. In: MENDES, Gilmar Ferreira; MORAIS, Carlos Blanco de (Orgs.). Mutações Constitucionais. São Paulo: Saraiva, 2016, p. 175-256. (Série IDP/Saraiva).

MENDES, Gilmar Ferreira. O papel do Senado Federal no controle de constitucionalidade: um caso clássico de mutação constitucional. Revista de Informação Legislativa, v. 41, n. 162, p. 149-168, 2004.

MIRANDA, Jorge. Caducidade das Normas Constitucionais. In: MENDES, Gilmar Ferreira; MORAIS, Carlos Blanco de (Orgs.). Mutações Constitucionais. São Paulo: Saraiva, 2016, p. 279-291. (Série IDP/Saraiva).

MIRANDA, Jorge. Os limites materiais da revisão constitucional. Revista Juridica, v. 13$14,1990$. 
MORAIS, Carlos Blanco de. As mutações constitucionais implícitas e seus limites jurídicos: autópsia de um Acórdão controverso. Jurismat, n. 3, p. 55-90, 2013.

NEJAIME, Douglas; SIEGEL, Reva. What Obergefell v. Hodges Should Have Said, Concurring Opinion. Rochester: Social Science Research Network, 2016. Disponível em: <https://papers.ssrn.com/abstract=2849644>. Acesso em: $11 \mathrm{dez} .2016$.

POST, Robert; SIEGEL, Reva. Roe Rage: Democratic Constitutionalism and Backlash. Harvard Civil Rights-Civil Liberties Law Review, v. 42, p. 373, 2007.

POST, Robert; SIEGEL, Reva B. Democratic Constitutionalism. In: SIEGEL, Reva B.; BALKIN, Jack M. (Orgs.). The Constitution in 2020. Nova York: Oxford University Press, 2009, p. 25-34.

RAMOS, Elival da Silva. Ativismo Judicial: Parâmetros Dogmáticos. São Paulo: Saraiva, 2010.

ROGEIRO, Nuno. Da Revisão Controlada: notas sobre o problema das cláusulas constitucionais irreformáveis. Polis, v. 1, p. 89-113, 1994.

SCHLINK, Bernhard. German Constitutional Culture in Transition. Cardozo Law Review, v. 14, p. 711, 1992 .

SCHMITT, Carl. Constitutional Theory. Trad. Jeffrey Seitzer. Durham: Duke University Press Books, 2008.

SCHMITT, Carl. Crisis of Parliamentary Democracy. Trad. Ellen Kennedy. Cambridge: The MIT Press, 1988.

SCHMITT, Carl. Hüter der Verfassung. Tübingen: J.C.B. Mohr, 1931. 
SCHMITT, Carl. Legality and Legitimacy. Trad. Jeffrey Seitzer. Durham: Duke University Press Books, 2004.

SIEGEL, Reva B. Constitutional Culture, Social Movement Conflict and Constitutional Change: The Case of the De Facto Era. California Law Review, v. 94, n. 5, p. 1323-1419, 2006.

SILVA, José Afonso da. Poder Constituinte e Poder Popular (Estudos sobre a Constituição). São Paulo: Malheiros Editores, 2000.

SILVA, José Afonso da. Teoria do Conhecimento Constitucional. São Paulo: Malheiros Editores, 2014.

SMEND, Rudolf. Constitution and Constitutional Law. In: JACOBSON, Arthur; SCHLINK, Bernhard. Weimar: A Jurisprudence of Crisis. Berkeley: University of California Press, 2002, p. 213-248.

STOLLEIS, Michael. A History of Public Law in Germany 1914-1945. Trad. Thomas Dunlap. Oxford: Oxford University Press, 2004.

STOLLEIS, Michael. Public Law in Germany, 1800-1914. Nova York: Berghahn Books, 2001.

STRAUSS, David A. The Living Constitution. Oxford: Oxford University Press, 2010.

STRECK, Lenio Luiz; BARRETTO, Vicente de Paulo; OLIVEIRA, Rafael Tomaz de. Ulisses e o canto das sereias: sobre ativismos judiciais e os perigos da instauração de um "terceiro turno da constituinte". Revista de Estudos Constitucionais, Hermenêutica e Teoria do Direito, v. 1, n. 2, p. 75-83, 2010. 
STRECK, Lenio Luiz; LIMA, Martonio Mont'Alverne Barreto; OLIVEIRA, Marcelo Andrade Cattoni de. A Nova Perspectiva do Supremo Tribunal Federal sobre o Controle Difuso: mutação constitucional e limites da legitimidade da jurisdição constitucional. Argumenta Journal Law, n. 7, p. 45-68, 2007.

SUnStEIN, Cass R. A Constitution of Many Minds: Why the Founding Document Doesn't Mean What It Meant Before. Princeton: Princeton University Press, 2011.

TREVINO, A. Javier. Classic Writings in Law and Society. Londres: Transaction Publishers, 2011.

TUSHNET, Mark V. Red, White, and Blue: A Critical Analysis of Constitutional Law. Lawrence: University Press of Kansas, 2015.

URRUTIA, Ana Victoria Sánchez. Mutación constitucional y fuerza normativa de la constitución: Una aproximación al origen del concepto. Revista Española de Derecho Constitucional, v. 20, n. 58, p. 105-135, 2000.

VERMEULE, Adrian. The Atrophy of Constitutional Powers. Oxford Journal of Legal Studies, v. 32, n. 3, p. 421-444, 2012.

VINX, Lars; KELSEN, Hans; SCHMITT, Carl. The Guardian of the Constitution: Hans Kelsen and Carl Schmitt on the Limits of Constitutional Law. Cambridge: Cambridge University Press, 2015.

WALDRON, Jeremy. The Core of the Case against Judicial Review. The Yale Law Journal, v. 115, n. 6, p. 1346-1406, 2006.

Sites e outras fontes: 
Americans' Attitudes Toward Abortion Unchanged. Gallup.com. Disponível em: <http://www.gallup.com/poll/191834/americans-attitudes-toward-abortion unchanged.aspx>. Acesso em: 13 dez. 2016.

History - Heidelberg University. Disponível em: <http://www.uniheidelberg.de/university/history/history.html>. Acesso em: 10 nov. 2016.

Mutação. In: Dicionário Houaiss da Língua Portuguesa. Rio de Janeiro: Objetiva, 2001.

Necrology: Hsü Dau-Lin. Sung Studies Newsletter. Disponível em: <http://www.humanities.uci.edu/eastasian/SungYuan/JSYS/Archive/SSN09.pdf>. Acesso em: 2 nov. 2016.

The Constitution of the United States. Disponível em: <http://constitutionus.com/>. Acesso em: $11 \mathrm{dez} .2016$.

Weimar Constitution. PSM database for preparing lessons in history. Disponível em: <http://www.zum.de/psm/weimar/weimar_vve.php\#Third Chapter>. Acesso em: 30 nov. 2016. 